\title{
Higher alveolar nitric oxide in COPD is related to poorer physical capacity and lower oxygen saturation after physical testing
}

\author{
To the Editor:
}

Exhaled nitric oxide (FENO) is an inflammatory marker used in asthma management but its clinical role in chronic obstructive pulmonary disease (COPD) is less defined. FENO represents the NO production in the airways. Various mathematical models have been used to gain information regarding peripheral NO from the lung [1]. NO from the gas exchange area is referred to as alveolar NO (CANO). CANO has been shown to be increased in symptomatic asthmatic subjects [2]; whereas in COPD, there is an alveolar destruction with emphysema and higher values of CANO have been reported [3-5]. However, in subjects with severe emphysema, there was no increase in CANO and, therefore, the clinical value of CANO is not clear [6]. CANO has been found to correlate negatively to the distance travelled in 6-min walking tests [5]. It is of interest that in athletes, hypoxaemia develops due to prolonged exercise [7] and in marathon runners who are regularly exposed to hypoxaemia during strenuous training, CANO values have been reported to be increased [8]. COPD patients frequently report dyspnoea with exertion, and our hypothesis was that repeated hypoxaemia could lead to an increase in CANO. We therefore investigated CANO in a Swedish study [9].

The study design and the methods used were previously described by HöGMAN et al. [9]. In short, patients in a stable condition who had been previously diagnosed by a physician as having COPD were recruited. The COPD diagnosis was confirmed at the study visit by a post-bronchodilator spirometry (SpiroPerfect spirometer; Welch Allyn, Skaneateles Falls, NY, USA). FENO at exhalation flows of 20, 100 and $300 \mathrm{~mL} \cdot \mathrm{s}^{-1}$ were measured in duplicate for the nonlinear modelling of NO exchange [1], which was in addition to $50 \mathrm{~mL} \cdot \mathrm{s}^{-1}\left(F \mathrm{ENO}_{50}\right)$. The Eco Medics CLD 88 (Eco Medics, Duernten, Switzerland) NO analyser was used with the Högman-Meriläinen algorithm software. Resting oxygen saturation measured by pulse oximetry $\left(\mathrm{SpO}_{2}\right)$ and $\mathrm{FENO}_{50}$ measurements were performed before any other tests. The physical tests, performed in random order, were the 30-m walking distance at maximal speed (30WT) and the 30-s chair-stand test (CST) $[10,11] . \mathrm{SpO}_{2}$ was measured with the WristOx2 Model 3150 (Nonin Medical BV, Amsterdam, the Netherlands). $\mathrm{SpO}_{2}$ analyses were made using the resting value before and the mean value after the two physical tests. Grouping variables were used for $\mathrm{SpO}_{2}$ with the 25th percentile of $91 \%$, CST with the 25th percentile of 10 repetitions and $30 \mathrm{WT}$ with the 75 th percentile of $\geqslant 20 \mathrm{~s}$ walking time. Nonparametric tests, i.e. Mann-Whitney U-test and Spearman's $\rho$ (SPSS version 24 for Windows; SPSS Inc., Chicago, IL, USA), were used for all statistical calculations. A p-value $<0.05$ was considered significant. Data are presented as median (interquartile range) with the exception of age and lung function (which are presented as mean \pm SD).

In total, $170 \mathrm{COPD}$ subjects (61\% female), aged $68 \pm 8$ years, had $\mathrm{FENO}_{50}$ levels of 13 (8-19) ppb and CANO levels of $1.4(0.7-2.3) \mathrm{ppb}$. Lung function measurements were: forced expiratory volume in $1 \mathrm{~s}(\mathrm{FEV} 1) 54$ $\pm 16 \%$ predicted and forced vital capacity (FVC) $67 \pm 16 \%$ predicted. In smokers $(\mathrm{n}=48), \mathrm{FENO}_{50}$ was significantly lower $8(5-14) \mathrm{ppb}$ than in ex-smokers $15(11-22) \mathrm{ppb}(\mathrm{p}<0.001)$ but for CANO, no difference was found $(1.3(0.7-2.1)$ and $1.4(0.7-2.4) \mathrm{ppb}$, respectively; $\mathrm{p}=0.46)$. This was also the case for $\mathrm{S}_{\mathrm{pO}_{2}}$

@ERSpublications

Nitric oxide from the gas exchange area, but not from the airways, is increased in subjects with chronic obstructive pulmonary disease with low oxygen saturation after physical testing http://bit.ly/ 2ItUJy6

Cite this article as: Högman $\mathrm{M}$, Thornadtsson $\mathrm{A}$, Bröms $\mathrm{K}$, et al. Higher alveolar nitric oxide in COPD is related to poorer physical capacity and lower oxygen saturation after physical testing. Eur Respir J 2019; 54: 1900263 [https://doi.org/10.1183/13993003.00263-2019]. 

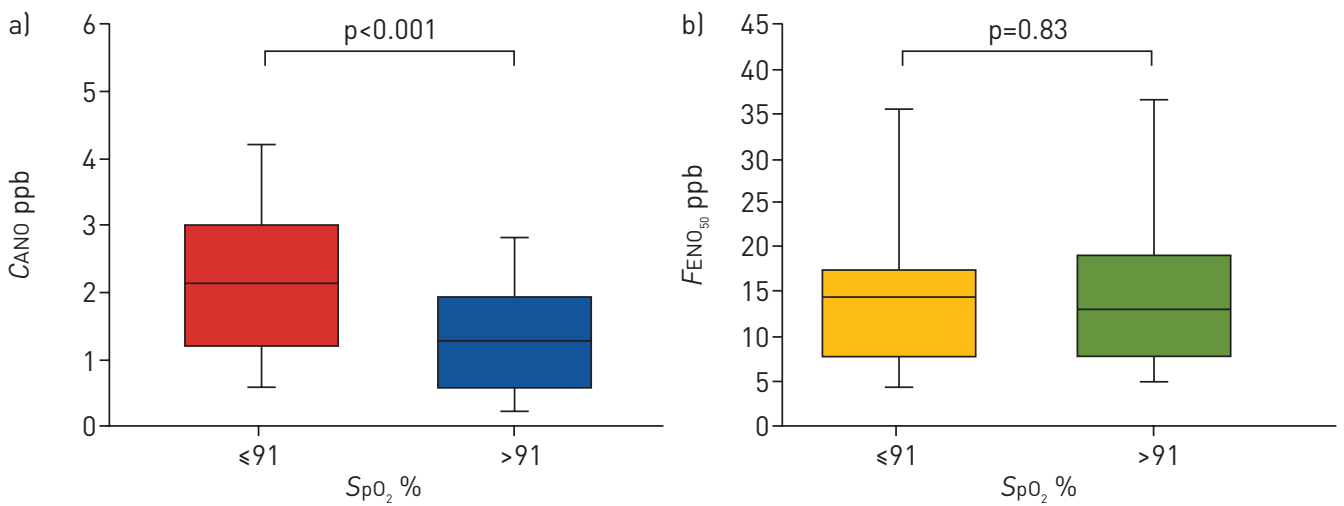

FIGURE 1 a) Alveolar nitric oxide content (CANO) was statistically significantly higher in the group with oxygen saturation measured by pulse oximetry $\left(\mathrm{SpO}_{2}\right) \leqslant 91 \%$ b) while no difference was found in exhaled nitric oxide fraction measured at $50 \mathrm{~mL} \cdot \mathrm{s}^{-1}\left(F_{E_{N} 0_{50}}\right)$. In the boxplots, the horizontal line in each box corresponds to the median value, the upper and lower margins correspond to the 25th and 75th percentiles, and the whiskers correspond to the 10th and 90th percentiles.

( $\mathrm{p}=0.46$ ). Therefore, subjects were not stratified by smoking status in the remaining analyses. The $30 \mathrm{WT}$ was $18(16-21) \mathrm{s}$ and the CST had $12(10-14)$ repetitions. $\mathrm{SpO}_{2}$ was significantly lower after physical testing compared to the resting value (93\% (91-94\%) and 95\% (93-96\%), respectively; $\mathrm{p}<0.001$ ). Significant correlations were found between CANO and $\mathrm{SpO}_{2}(\rho=-0.29, \mathrm{p}<0.001)$, the difference in $\mathrm{SpO}_{2}$ pre- and post-physical testing $(\rho=0.25, p=0.001)$, age $(\rho=0.19, p=0.012), 30 \mathrm{WT}(\rho=0.17, p=0.03)$ and CTS $(\rho=-0.16, p=0.044)$ but not to blood eosinophil levels. $F_{E N O}$ was correlated to lung function, FEV1 \% predicted $(\rho=0.16, p=0.044)$, FVC $\%$ predicted $(\rho=0.16, p=0.034)$ and blood eosinophil levels $(\rho=0.24$, $\mathrm{p}=0.002)$.

When stratifying subjects into $\mathrm{SpO}_{2} \leqslant 91 \%(\mathrm{n}=47)$ or $>91 \%(\mathrm{n}=123)$, there was a difference in CANO $(\mathrm{p}<0.001)$ but not in $\mathrm{FENO}_{50}(\mathrm{p}=0.83)$ (figure 1). Subjects with $\mathrm{SpO}_{2} \leqslant 91 \%$ had fewer repetitions in the CST (10 (9-12) and $13(11-15)$, respectively; $\mathrm{p}=0.001)$ and longer times for the 30WT (19 (18-23) and 17 $(16-20) \mathrm{s}$, respectively; $\mathrm{p}<0.001)$.

This study has found that CANO, but not FENO, is increased in subjects with low $\mathrm{SpO}_{2}$ after physical testing. Subjects with a low $\mathrm{SpO}_{2}$ performed worse in the physical tests. Unlike FENO, CANO is not affected by smoking. Subjects who had $\mathrm{SpO}_{2} \leqslant 91 \%$ had a higher CANO; this could suggest that in COPD subjects, there is a potential for the lung to adapt to dyspnoea. We did not perform arterial oxygen saturation analysis but it has been shown that $\mathrm{SpO}_{2}$ accurately reflects arterial oxygen saturation with exercise. Further research is needed to explore the reason for the increase in CANO in COPD subjects. Longitudinal studies of CANO in COPD subjects are needed to understand whether CANO has the potential to be a prognostic biomarker of pulmonary performance.

Marieann Högman ${ }^{1}$, Alexandra Thornadtsson ${ }^{1,2}$, Kristina Bröms ${ }^{2,3}$, Christer Janson ${ }^{1}$, Karin Lisspers ${ }^{3,4}$, Björn Ställberg ${ }^{3,4}$, Hans Hedenström ${ }^{5}$ and Andrei Malinovschi ${ }^{5}$

${ }^{1}$ Dept of Medical Sciences, Respiratory, Allergy and Sleep Research, Uppsala University, Uppsala, Sweden. ${ }^{2}$ Center for Research and Development, Uppsala University/Region Gävleborg, Gävle, Sweden. ${ }^{3}$ Dept of Public Health and Caring Sciences, Family Medicine and Preventive Medicine, Uppsala University, Uppsala, Sweden. ${ }^{4}$ Center for Clinical Research, Uppsala University, County Council Dalarna, Falun, Sweden. ${ }^{5}$ Dept of Medical Sciences, Clinical Physiology, Uppsala University, Uppsala, Sweden.

Correspondence: Marieann Högman, Dept of Medical Sciences, Respiratory, Allergy and Sleep Research, Uppsala University, University Hospital, S 75185 Uppsala, Sweden. E-mail: marieann.hogman@medsci.uu.se

Received: Feb 262019 | Accepted after revision: April 132019

Conflict of interest: None declared.

\section{References}

1 Horvath I, Barnes PJ, Loukides S, et al. A European Respiratory Society technical standard: exhaled biomarkers in lung disease. Eur Respir J 2017; 49: 1600965.

2 Lehtimäki L, Kankaanranta H, Saarelainen S, et al. Extended exhaled NO measurement differentiates between alveolar and bronchial inflammation. Am J Respir Crit Care Med 2001; 163: 1557-1561.

3 Brindicci C, Ito K, Resta O, et al. Exhaled nitric oxide from lung periphery is increased in COPD. Eur Respir J 2005; 26: 52-59. 
4 Williamson PA, Clearie K, Menzies D, et al. Assessment of small-airways disease using alveolar nitric oxide and impulse oscillometry in asthma and COPD. Lung 2011; 189: 121-129.

5 McCurdy MR, Sharafkhaneh A, Abdel-Monem H, et al. Exhaled nitric oxide parameters and functional capacity in chronic obstructive pulmonary disease. J Breath Res 2011; 5: 016003.

6 Bazeghi N, Gerds TA, Budtz-Jorgensen E, et al. Exhaled nitric oxide measure using multiple flows in clinically relevant subgroups of COPD. Respir Med 2011; 105: 1338-1344.

7 Hopkins SR, Gavin TP, Siafakas NM, et al. Effect of prolonged, heavy exercise on pulmonary gas exchange in athletes. J Appl Physiol 1998; 85: 1523-1532.

8 Thornadtsson A, Drca N, Ricciardolo F, et al. Increased levels of alveolar and airway exhaled nitric oxide in runners. Ups J Med Sci 2017; 122: 85-91.

9 Högman M, Sulku J, Ställberg B, et al. 2017 Global Initiative for Chronic Obstructive Lung Disease reclassifies half of COPD subjects to lower risk group. Int J Chron Obstruct Pulmon Dis 2018; 13: 165-173.

10 Andersson M, Moberg L, Svantesson U, et al. Measuring walking speed in COPD: test-retest reliability of the 30-metre walk test and comparison with the 6-minute walk test. Prim Care Respir J 2011; 20: 434-440.

11 Jones CJ, Rikli RE, Beam WC. A 30-s chair-stand test as a measure of lower body strength in community-residing older adults. Res Q Exerc Sport 1999; 70: 113-119. 